\title{
Improving the Status of Human and Material Resources in Public Primary Schools in Oyo States towards Achieving the Millennium Development Goals Project
}

Kolawole, Clement Olusegun Olaniran

\begin{abstract}
This study considered some selected public primary schools in Oyo State in order to determine the status of human and material resources available there so that a case can be made for their improvement towards the achievement of one of the cardinal goals of the Millennium Development Goals project in the State. To carry out the survey, a self-constructed questionnaire that was adjudged valid content-wise by experts in the field was used to gather information from the Headmasters of the schools selected over a period of two months. Descriptive statistics of frequency and percentage was used to analyse the data generated. It was discovered that grades I, II and III schools were involved in the study, the quality of primary school teachers in terms of qualification was high, most of the schools had inadequate teachers and classroom space, there were no well-stocked libraries, well-equipped first aid centres, adequate electronically projected instructional materials such as computers, counselling centres as well as recreational facilities among others. Based on this discovery, it was recommended that the government of the State should provide these facilities in public primary schools in order to make it possible for the achievement of the Millennium Development Goals project.
\end{abstract}

\section{Introduction}

A major aim of education in Nigeria, from the primary to the tertiary level, was to produce educated people who would be able to meet the manpower needs of the country. In order to achieve this lofty aim in an enduring manner, the government has come to see primary education as the foundation upon which any successful educational enterprise, at the secondary and tertiary levels, is based. Thus, the 
government made provision for the achievement of an enduring primary school education because it is believed that at the end of primary school education, the individual concerned must have 'achieved permanent literacy and numeracy in the language of the immediate community and will be able to function normally in the world of work' (FRN, 2004, p.). This is because Nwangwu (1978) had previously remarked that the foundation upon which the rest of the educational system is built is the primary school.

The government has also liberalized ownership of primary school so that it can collaborate with private interest to make sure that primary education achieves it objectives. To this end, two types of primary education namely, private and public primary school system now exist. But unfortunately, the private primary school system is being run by individuals whose sole aim of providing that kind of education is to make profit. Such schools have adequate facilities and are closely monitored by their proprietors/proprietresses so that they will continue to attract quality clientele; the public primary school system has been left to decay due to several problems. In spite of the problems which confront public primary schools in Nigeria and Oyo State, the government has not failed to make it clear that it sees primary schools as the pivot upon which the success of the nation's educational enterprise rests.

To further support the importance of primary education in the educational development of the country, the National Policy of Education (2004) stated clearly that primary education in Nigeria would be expected to achieve the following objectives:

i) the inculcation of permanent literacy and numeracy and the ability to communicative effectively;

ii) the laying of a sound basis for scientific and reflective thinking;

iii) character and moral training and the development of sound attitude; 
iv) giving the child the opportunities for developing manipulative skills that will enable him/her to function effectively in the society;

v) providing basic tools for further educational advancement, including preparation for trades and crafts of the society;

vi) developing in the child the ability to adapt to his changing environment

It is a common knowledge that in an attempt to meeting these objectives, the government, at all levels has been making huge financial allocations to the primary level so that it can be properly equipped in terms of staffing, provision of infrastructural facilities and improved curricula. According to Gbadamosi (2000), the changes that have taken place in the primary school system have also led to adjustments in the areas of curriculum and instruction, organization and management, teacher qualifications, teacher-pupils ration, pupils enrolment and the like. In a specific term, the government has made the National Certificate in Education the minimum teaching qualification at the primary school level in order to facilitate the laying of a sound basis for acquisition of knowledge.

Unfortunately, the introduction of the Universal Basic Education in 1999 by the federal government did not effectively address the problem of lack of access to primary school due to many factors part of which the programme was to address. The introduction of Education For All campaign and the Millennium Development Goals in 2000 thus made it compulsory for countries to create more access for their children to receive basic education in order to achieve one of the goals of the MDG which is 'achieving universal primary education before 2015 '.

Part of the efforts made by the government to monitor what goes on in the primary school in order to achieve good standard, have facilities in place, facilitate improvement in enrolment (after most parents had withdrawn their children from public primary schools due to incessant teachers strike over unpaid salaries and virtual collapse of 
infrastructural facilities) and improve the quality and quantity of teachers was the introduction of the Universal Basic Education (UBE) in 1999. This was introduced twenty-three years after the UPE which did not meet the expectation of the populace was launched. The UBE was therefore packaged to address the problem of access to primary education, provision of qualified teachers and general infrastructural facilities in primary schools nation-wide. It was designed to cover primary school and the first three years of secondary education so that "every individual child, youth and adult with sound knowledge, skills and attitudes that will enable him/her to develop to his or her fullest capacity, derive maximum social, economic and cultural benefits from his/her membership of the society and fulfil his/her civic obligations'.

The Universal Basic Education was introduced to enhance increased enrolment, retention and completion in basic education and promote the quality of basic education among other objectives. This position was taken because the government had come to realize, albeit lately, that facilities for the delivery of a sound universal primary education are still grossly inadequate, the pupil-teacher ratio is very high, teachers were not adequately trained and motivated, classrooms were generally over-crowded, there is general poor learning environment and inadequacy of relevant instructional materials and guides. (Blueprint on Basic Education, FRN, 1999). Recently, it was reported that 145,000 primary school teachers across the country were of poor quality and needed to be re-trained by the National Teachers Institute through the Millennium Development Goals project if they are to give quality education to children at the public primary school level (Akhaine, 2006).

The situation in Oyo State public primary school system is not different from what is happening in other public primary schools in the country. This is in spite of the huge financial commitment on the part of the federal government to primary education through the creation of the Universal Basic Education Commission at the federal level and State Universal Basic Education Boards at the state level to ensure that there is a remarkable change in the situation of public 
primary school. Eight years in the life of the UBE is enough for it to be assessed in order to finding out what is on ground to make the achievement of one of the cardinal objectives of the Millennium Development Goals Project a reality. This is from the background that the immediate past government in the state introduced a radical programme that re-positioned primary school in active connivance with the Universal Basic Education Commission. The State Universal Basic Education Board was adequately funded by the government so that it could improve the infrastructural facility at the state primary school, improve the quality and quantity of teachers and motivate them to perform their duties well.

\section{Statement of the Problem}

The expectation today is that there is a change in the situation of human and materials resources available at the primary school level eight years after the introduction of the Universal Basic Education to position that level of education for the achievement of one of the goals of the Millennium Development Goals project. This study therefore set out to survey the status of two important variables that are essential in order to determine their state in readiness for the MDG project.

To carry out the survey, the following research questions were raised and answered:

i) What is the current state of teachers in terms of quality and quantity in public primary school in the State?

ii) Do public primary schools now have adequate classroom resources (in terms of adequate space, instructional and supporting facilities)?

iii) Is there any difference between the urban and rural school in terms of availability of classroom resources and teachers?

iv) What is the teacher-pupil ratio now in the schools? 
v) Are primary schools now properly equipped in terms of the provision of modern facilities, library resources and conducive learning environment?

\section{Procedure}

To carry out the survey, a researcher designed instrument questionnaire which was content and face validated by experts in the field was administered randomly in selected towns in Oyo State with the aid of research assistants. The towns were selected from the three senatorial zones of the State. Specifically, the headmasters of the schools chosen were asked to complete the questionnaire which was collated for analysis three weeks later. The information collected from the questionnaire was used to answer the research questions used in the study.

\section{Results and Discussions}

Data analysis showed that $140(93 \%)$ of the teachers in the primary schools sampled for this study hold the NCE which is the minimum teaching qualification at that level. In addition, $9(6 \%)$ hold university degrees and $1(0.66 \%)$ holds the Grade II teachers certificate. This shows that the quality of teachers at the primary school level in the State has improved significantly. Further analysis showed that $70 \%$ of the schools do not have adequate number of teachers to teach in spite of the fact that qualified teachers were available in the primary school system while only (30\%) of the schools have the required number of teachers. In all the 150 schools sampled, a total number of 2,453 teachers were expected to be available based on the response to the question on actual number of teachers that are actually expected to be in the schools. This information showed that even though the quality of teachers at the primary school level in Oyo State has improved, the number in terms of quantity was not enough. Thus, question 1 has been answered. It is clear that the quality of primary school teachers was high but the quantity was low. This position further showed that teaching and learning in the public primary schools will be in serious problem since the required man-power was not adequately available in 
spite of the effort of government to make sure that highly qualified teachers were posted to the schools.

On the availability of adequate classroom space, information available showed that 100 schools do not had adequate classroom space for children while only 50 schools have adequate classroom space mostly in the rural schools where the number of pupils was not many. Some teachers in the urban schools have to resort to merging classes to make sure that two different arms of a class are put together in one room. Evidence showed that out of the required 1,582 classrooms expected across the schools it was discovered that, only 982 representing $62 \%$ classrooms are actually available. Most classrooms in the schools had been abandoned because they had collapsed while others were undergoing renovation. This situation called for immediate attention because the non-availability of classroom space could pose a dangerous trend to the successful implementation of the (UBE) programme and the achievement of the MDG in the State. Information further showed that most of the schools in urban centres across the State had the problem of inadequate classroom space due to population increase and the collapse of most of the building housing primary school pupils. From this information, it is clear that research question 2 cannot be answered in a positive sense.

In order to determine the status of the school, an analysis was made based on the response to the items on the status of the schools. $80(53 \%)$ of the schools are categorized as grade I with a total population of 26,414 pupils, $50(33 \%)$ of the schools are grade II with a population of 16,509 while $20(13 \%)$ is classified at grade III with a total population of 6,604 pupils. This showed that grade I schools had more pupils than the other two grades II and III put together. The implication of this was that grade I schools were expected to have more teachers, pupils and facilities. But this was not the case because most primary schools in Ibadan city were not conducive enough for learning due to lack of facilities and adequate space. It could be concluded that there was a major difference between urban and rural 
schools in terms of availability of classroom, teaching resources and teachers thus answering question 3.

In terms of pupil-teacher ratio, the normal ratio of teacher-pupils in primary schools according to the National Policy on Education (2004) was 1.25. The situation in the school sampled showed the teacherpupil ratio in public primary schools in Oyo State

From the information, it was clear that only $20 \%$ of the schools had the normal official ratio of 1.25. In most of the schools, the ratio is either too low or too high with the implication that in $54 \%$ of the schools, the number of teachers was more than the number of pupils while in others, there were more pupils than teachers. This indicated that the government had to look into the posting of teachers to schools in order to make sure that while some schools were not over-staffed, others were not short-staffed. This is one way by which the schools can be made ready to cater for the large population being expected in school in line with the MDG project. The teacher-pupil ratio was not in accordance with the requirement of the law as indicated in the (NPE) previously cited above.

Information showed that all the one hundred and fifty public primary schools visited had blackboards, charts of various shades and colours showing parts of the body, rivers in Africa and Nigeria, various tribal groups in the country and other crops produced in the country. These charts were being used in the teaching of social studies, health education and family life education. But unfortunately, none of them had electronically operated materials/facilities such as computers, overhead projectors, slides, DVDs, videos and the like, well-stocked libraries, well-equipped first aid boxes, modern toilet facilities counselling centres and facilities for recreational activities. It is obvious from this background that public primary schools in Oyo State were poorly equipped and were not in a position to provide practical and meaningful education for children at that level unless something drastic was done about the situation. Isolated resources centres built with the assistance of non-governmental organizations 
and the UNICEF could be found in one school in a local government across the state. This was not enough to position public primary schools to achieve the objectives that had been set for it. So, it could be concluded that in spite of the huge sums of money being pumped into public primary education in Oyo State, question five cannot be answered in the affirmative.

The general state of resources in the schools sampled calls for a complete re-orientation on the part of the people whose duty it was to make sure that the primary school system was adequately equipped to position it for the big task of meeting the MDG project objectives. The discovery in this research agrees with a previous finding in Kolawole (2007) and with this discovery, it is obvious that public primary schools were not properly equipped and the government has to make them (facilities and materials) available in adequate quantity if the much orchestrated (UBE) was not to go the way of previous efforts at improving primary education in Oyo State in particular and Nigeria in general.

\section{Discussions}

The finding of this research had shown that even though almost all primary school teachers in the State had the required teaching qualifications, teachers were not adequate in the school system. Similarly, classrooms were not adequate while both urban and rural as well as grade I, II and III schools did not comply with the nationally accepted teacher-pupil ratio. It was also revealed that all the schools do not have modern facilities that could facilitate easy teaching and learning at that level of education.

This finding has serious implications on curriculum implementation at that level of education and can pose a threat to the realization of the objectives of primary school as enunciated in the National Policy on Education previously cited in this paper. Some of the implications were that the teachers and the classrooms where curriculum was to be implemented were not adequately made available. Where then will teaching and learning take place? In order to take care of this short- 
fall, classes were merged while the few available teachers and classrooms were over-stretched thus negatively affecting the quality of instruction that was given. We found various situations where two classes are in one classroom with little or no partition to separate them. Besides, materials that would have enhanced the quality of instruction in the few available classrooms were grossly not available so the teachers are further over-burdened. Thus, no meaningful curriculum can be implemented successfully in a situation like that.

In addition to facilities, none of the schools had a well-stocked library where pupils could resort to when they needed to explore the world or read. They are thus not able to fully lay the foundation for later reading in their secondary school and later life. This had further made it impossible for one of the objectives of primary education which was preparation for secondary school education to be achieved. When aims were difficult to achieve, education will inexorably be in shambles. The absence of modern toilets and recreational facilities and counselling services at that level casts a big shadow on our attempt at making it easy for teachers to fully implement the wellarticulated curriculum prepared for pupils at the primary school level in line with the requirements of the MDG project.

The issues raised in this research were strong enough to make a mess of curriculum implementation generally because pupils cannot fully exercise their mental and physical faculties at school due to lack of basic facilities and conducive environment. Besides, both the gross and motor skills which ought to be exercised to facilitate proper development were not given the chance to do so. Instead of teachers paying close attention to the over-all growth of the pupils, they merely concentrate on the cognitive aspect alone and when the children grow up; they find it difficult to adjust to normal school programmes easily. This could be why most pupils who attend private primary schools where these materials are available perform much better than their mates who attend public primary school. It is a fact today that most primary school pupils in public schools cannot read the text that their counterparts in private primary schools can read fluently and they 
cannot solve simple mathematics problems their counterparts could solve. It is a pity because both schools are expected to prepare the children for the same Nigerian society. There is no doubt that something very drastic has to be done to redress this situation in line with the objective of the MDG project.

\section{Conclusion}

It is a known fact that however good a curriculum is, its implementation will positively or negatively affect the results that is got. In the same way, however lofty objectives at any level of education may be, its implementation depends on the availability of qualified teachers and conducive environment. There is no doubt that the results will be negative when the materials and conditions for the successful implementation of the curriculum are not available. This is why the products of our public primary schools are generally disadvantaged in terms of their performance in academic and sporting activities.

Government at all levels in Nigeria, as a matter of urgency, have to hasten the provision of qualified teachers, adequate classrooms and modern facilities and convenience in our public primary schools so that a very positive and qualitative foundation for education can be laid at that level for our children. The (UBE) programme which has been designed to prepare these children to meet the challenges of the $21^{\text {st }}$ century cannot succeed without these basic conditions.

Finally, the government, based on its conviction that it sees primary education as the foundation of education in Nigeria must make sure that the foundation is solidly laid if Nigeria is to be able to meet its man-power need and be able to take its rightful place more forcefully in the comity of nations where elementary education has been elevated to the right level. To meet the objective of the MDG project on primary education requires Nigeria to rise to the occasion and made public primary school what it should be. 


\section{References}

Akhaine, S. (2006). "Government to Retrain 145,000 Teachers." The Guardian. Tuesday, August 5, P. 5

Federal Republic of Nigeria (1999). Blueprint on Basic Education. Abuja, Federal Ministry of Education

Federal Republic of Nigeria (2004). National Policy on Education. Yaba, NERDC

Gbadamosi, B. (2000). "Trend in the development of primary education in Ogun State of Nigeria: 1991 - 1998." Unpublished Ph.D Thesis, University of Ibadan

Kolawole, C. O. O. (2007) "Availability and Utilization of AudioVisual Materials for the Teaching of English Language in Selected Nursery/Primary Schools in Ibadan." Journal of Historical Sciences. Vol 2, No. 1

Nwangwu, N. A. (1978). Universal Primary Education in Nigeria: Issues, Prospect and Problems. Benin City. Ethiope Publishing Corporation 